\title{
Câncer de colo uterino e a infecção pelo HPV: consequências da não adesão aos métodos de prevenção
}

\author{
Cervical cancer and HPV infection: consequences of non-adherence to prevention \\ methods
}
Cáncer de cuello uterino y infección por HPV: consecuencias de la no adherencia a los métodos de prevención

Laís Guedes Rodrigues ${ }^{1 *}$, Karine Brito Matos Santos ${ }^{1}$, Ana Carolina da Silva Soares Martins ${ }^{1}$, Bruna Lorena Silva Fagundes², Valeska Cardoso Oliveira², Maria Cecília Ataíde Gomes², Ravena Cristina Silva de Sousa ${ }^{3}$.

\section{RESUMO}

Objetivo: Identificar se a vacinação contra o HPV é acessível para o público-alvo e avaliar se os métodos para diagnóstico precoce se aplicam à realidade da população. Métodos: A pesquisa caracteriza-se como uma revisão integrativa de literatura que utilizou como ferramentas de busca as seguintes bases de dados: Literatura Latino-Americana e do Caribe em Ciências da Saúde (LILACS), ScientificElectronic Library Online (SCIELO) e Medical Literature Analysis and Retrieval System Online (MEDLINE). Os Descritores em Ciências da Saúde (DECS) utilizados para busca foram: "câncer de colo uterino, Papilomavírus humano, infecção e vacinação". Resultados: Observou-se que o câncer cervical é o terceiro mais frequente na população feminina e quarta causa mais comum de morte entre as mulheres no Brasil. A infecção pelo HPV acontece principalmente em jovens após o início da vida sexual e estima-se que 660 milhões de pessoas no mundo já tiveram contato com o vírus. Considerações finais: Este estudo é de fundamental importância, pois irá garantir embasamento para a comunidade científica e acadêmica acerca da falta de adesão das mulheres na realização de exames preventivos e falta de informação quanto à importância da vacinação contra o HPV para a prevenção do câncer, o que diminui a taxa de vacinação.

Palavras-chave: Câncer de colo uterino, Papilomavírus humano, Infecção, Vacinação.

\begin{abstract}
Objective: To identify whether vaccination against HPV is accessible to the target audience and to assess whether methods for early diagnosis apply to the reality of the Brazilian female population. Methods: The research is characterized as an integrative literature review, that was performed using the following databases as search tools: Latin American and Caribbean Literature in Health Sciences (LILACS), Scientific Electronic Library Online (SCIELO) and Medical Literature Analysis and Retrieval System Online (MEDLINE). The Health Sciences Descriptors used for the search were: "cervical cancer, human Papillomavirus, infection and vaccination". Results: It was observed that cervical cancer is the third most common in the female population and the fourth most common cause of death among women in Brazil. HPV infection occurs mainly in young people after sexual debut and it is estimated that 660 million people worldwide have had contact with the virus. Final considerations: This study is of fundamental importance, as it will guarantee basis for the scientific and academic community about the lack of adherence of women in carrying out preventive exams and lack of information regarding the importance of HPV vaccination for prevention cancer, what decreases the rate of vaccination.
\end{abstract}

Keywords: Cervical cancer, Human papillomavirus, Infection, Vaccination.

\footnotetext{
1 Faculdades Santo Agostinho (FASA), Vitória da Conquista - BA. *E-mail: laisguedes29@gmail.com

2 Faculdades Unidas do Norte de Minas, Montes Claros - MG.

${ }^{3}$ Centro Universitário Facid Wyden, Teresina - PI.
} 


\section{RESUMEN}

Objetivo: Identificar si la vacunación contra HPV es accesible al público objetivo y evaluar si los métodos de diagnóstico precoz se aplican a la realidad de población femenina brasileña. Métodos: La investigación se caracteriza por ser una revisión integradora de la literatura, se realizó utilizando las bases de datos: Literatura Latinoamericana y del Caribe en Ciencias de la Salud (LILACS), SCIELO y Sistema de Análisis y Recuperación de Literatura Médica en Línea (MEDLINE). Los Descriptores de Ciencias de la Salud utilizados fueron: "cáncer de cuello uterino, HPV, infección y vacunación". Resultados: Se observó que el cáncer de regazo uterino es el tercer más común y cuarta causa más común de muerte entre mujeres en Brasil. La infección por HPV ocurre principalmente en jóvenes después de las relaciones sexuales debutan y se estima que 660 millones de personas en todo mundo han tenido contacto con el vírus. Consideraciones finales: Este estudio es de fundamental importancia, ya que garantizará una base para la comunidad científica y académica sobre la falta de adherencia de las mujeres en realización de exámenes preventivos y falta de información sobre importancia de la vacunación contra HPV para la prevención del câncer, que disminuye la tasa de vacunación.

Palabras clave: Cáncer de regazo uterino, Virus del papiloma humano, Infección, Vacunación.

\section{INTRODUÇÃO}

O câncer de colo do útero é considerado um importante problema de saúde pública, pois é um tipo de câncer ginecológico muito frequente em mulheres no Brasil devido ao grande número de pacientes que não realizam exames preventivos regularmente e não se imunizaram contra o HPV, apresentando altas taxas de incidência e mortalidade. O Instituto Nacional de Câncer (INCA) estima o surgimento de 16.340 novos casos de câncer cervical por ano, representando 7,9\% do total, e 5.430 óbitos anuais (INCA, 2017).

Esse tipo de câncer apresenta várias etiologias, sendo destaque a íntima relação com a presença do Papilomavírus humano (HPV), visto que este tem seu DNA presente em mais de $99 \%$ dos casos de câncer de colo uterino. O HPV é um adenovírus pertencente à família Papillomaviridae que afeta pele e mucosas, causando verrugas genitais, lesões precursoras e câncer que necessitam de tratamentos recorrentes e desconfortáveis (BERNARD HU, et al., 2010). Além do câncer de colo uterino, o HPV se associa também com neoplasias vulvares, penianas, anais e de cabeça e pescoço. Existem vários tipos de HPV, dentre eles os tipos oncogênicos 16 e 18 que são mais frequentemente associados ao câncer e os tipos HPV-6 e HPV11 associados à condilomas acuminados e papilomatose recorrente juvenil (WORLD HEALTH ORGANIZATION (WHO), 2016).

O HPV é um vírus de DNA com forma icosaédrica, mede cerca de $55 \mathrm{~nm}$ de diâmetro e é composto por 8000 pares de bases. Possui genes que expressam proteínas precoces (early - E1 a E7) e tardias (late - L1 e L2) (VILLIERS EM, 2013). São adenovírus da família Papillomaviridae e apresentam grande variedade de hospedeiros, que incluem o homem e alguns animais. O HPV passou a ganhar importância após a descoberta da sua associação com o câncer de colo de útero, sendo detectado em $99,7 \%$ dos casos dessa neoplasia (WHO, 2016). Existem mais de 200 tipos de HPV e cerca de 20 podem infectar o trato genital. Os tipos mais frequentemente associados ao câncer são os tipos HPV-16 e HPV-18, sendo os tipos 6 e 11 associados a $90 \%$ dos condilomas acuminados e papilomatose recorrente juvenil.

Existem dois grupos de HPV que são divididos segundo o potencial oncogênico: os tipos 6, 11, 40, 42, 43, 54, 61, 70, 72, 81, CP6 108 apresentam baixo potencial oncogênico, desenvolvendo condilomas e lesões de baixo grau. Já os tipos $16,18,31,33,35,39,45,51,52,56,58,59,68,73$ e 82 são considerados de alto risco oncogênico (BERNARD HU, et al., 2010). A transmissão viral acontece pelo contato sexual pele a pele ou pele-mucosa. No primeiro contato sexual, uma em cada dez mulheres é contaminada e, após três anos com o mesmo parceiro, $46 \%$ delas já terão adquirido o vírus. O HPV entra no epitélio pelas microfissuras ou no colo uterino pelas células metaplásicas e atinge as células das camadas mais profundas, infectando-as (RABACHINI T, et al., 2012).

Esse tipo de vírus produz pouco processo inflamatório, causando pouco estímulo imunológico no organismo do hospedeiro, além de apresentar ação que inibe o sistema imune. Por isso o HPV tende a 
escapar da resposta imune do hospedeiro e pode permanecer latente por tempo indeterminado, ou chegar às camadas superficiais do epitélio, pela maturação e diferenciação das camadas epiteliais (SASAGAWA T, et al., 2012). O vírus pode assumir duas formas de atuação na célula: a forma epissomal, responsável pela produção das cópias virais; ou a forma integrada ao DNA do organismo hospedeiro, podendo iniciar o processo de oncogênese na presença de outros fatores de risco (BRASIL, 2014).

A ação viral provoca o surgimento de lesões intraepiteliais escamosas (SIL) e quando estas estão na forma de lesão de alto grau (HSIL) ou neoplasia intraepitelial de alto grau (NIC 2 e 3), são consideradas as lesões precursoras "verdadeiras" do câncer cervical (NEVES NA, 2010). As lesões induzidas pelo HPV podem entrar em remissão espontânea em até dois anos, principalmente as de baixo grau. Apesar disso, a imunidade humoral pode não prevenir contra novas infecções uma vez que os níveis de anticorpos produzidos são baixos e podem se negativar. As lesões de vagina, neoplasias intraepiteliais vaginais (NIVA) e vulva (NIV), são menos frequentes que as lesões de colo, mas também são induzidas pelos HPV de alto risco (INCA, 2016).

A vacinação contra o HPV é o método mais indicado para prevenir a infecção por esse vírus e, consequentemente, o câncer de colo de útero. A vacina quadrivalente foi incorporada ao calendário do Sistema Único de Saúde em 2014 e confere proteção contra os tipos 6, 11, 16 e 18 do HPV (NEVES NA, 2010). Esta imunização inicialmente era feita em meninas entre 9 e 11 anos de idade e a partir de 2017 passou a incluir meninos entre 11 e 14 anos, além de homens e mulheres transplantados, pacientes oncológicos e crianças e jovens entre 9 e 26 anos portadores de HIV-Aids (BRASIL, 2017). Entretanto, no Brasil ainda não foi adotada a estratégia de vacinação em escolas, como acontece nos países desenvolvidos, o que dificulta a cobertura de pelo menos $80 \%$ da população (SASAGAWA T, et al., 2012).

Além da vacinação, outra forma de prevenção contra o HPV é através do rastreamento realizado a partir de exames como a colposcopia, exame citopatológico e biópsia, visto que nos estágios iniciais a doença é assintomática ou apresenta sintomas inespecíficos. O rastreamento para câncer cervical está disponível para mulheres entre 25 e 64 anos de idade nas Unidades Básicas de Saúde (UBS) (INCA, 2016). Porém, no Brasil, cerca de seis milhões de mulheres entre 35 e 49 anos nunca realizaram exame citopatológico (Papanicolau), sendo essa a faixa etária que apresenta o maior número de casos positivos para câncer cervical (BRASIL, 2012). O Papanicolau é o exame padrão ouro para rastreio de câncer de colo de útero, pois através da análise das células da ectocérvice e endocérvice é possível identificar a presença do HPV além de outras alterações (INCA, 2017).

Em 2018, a Organização Mundial da Saúde (OMS) estabeleceu metas para o combate ao câncer de colo uterino que devem ser cumpridas até 2030 , dentre elas se destacam a vacinação de $90 \%$ das meninas com até 15 anos de idade e realização do exame Papanicolau em pelo menos 30\% das mulheres entre 25 e 64 anos de idade que já tenham iniciado a vida sexual (WORLD HEALTH ORGANIZATION (WHO), 2016).

Além da infecção pelo HPV, o câncer cervical possui outros fatores de risco, como o tabagismo, histórico familiar e presença de doenças imunossupressoras. Histórico sexual: ter atitudes como início precoce de vida sexual, se relacionar com muitos parceiros ou com um parceiro considerado de alto risco (com alguma infecção sexualmente transmissível) aumentam o risco de desenvolvimento de câncer cervical, devido ao contato com patógenos (WORLD HEALTH ORGANIZATION (WHO), 2011). Tabagismo: mulheres que fumam têm o dobro de probabilidade de desenvolver a doença, devido à presença de produtos químicos cancerígenos específicos que podem danificar o DNA das células do colo uterino, propiciando o processo neoplásico. Além disso, o ato de fumar causa prejuízos no sistema imunológico tornando-o mais vulnerável (DALY SF, et al., 2012). Imunossupressão: mulheres que possuem doenças imunossupressoras, como, por exemplo, as portadoras do vírus da imunodeficiência humana (HIV), podem ter o desenvolvimento mais rápido de uma lesão pré-cancerígena (SCHIFFMAN M, 2011). Infecção por clamídia: a clamídia é uma bactéria transmitida pelo contato sexual que pode infectar o sistema reprodutivo. Essa infecção pode causar inflamação pélvica, infertilidade e câncer cervical (INTERNATIONAL FEDERATION OF GYNECOLOGY \& OBSTETRICS (FIGO), 2010). Situação socioeconômica: mulheres de classes econômicas mais baixas e com baixo grau de escolaridade podem ter mais dificuldade em acessar o serviço de saúde, deixando de fazer exames importantes de rastreamento para diagnóstico precoce. 
O tratamento do câncer cervical, que pode ser realizado tanto na rede pública como na rede privada, consiste em conização, Cirurgia de Alta Frequência (CAF), radioterapia ou quimioterapia a depender do grau da lesão intraepitelial. Esses tipos de tratamento podem gerar sequelas ao assoalho pélvico, levando a distúrbios nos sistemas urinário e genital, como urgência miccional e dificuldade para manter relações sexuais (CORRÊA CSL, et al., 2016).

É importante ressaltar que mesmo após o tratamento da lesão, a mulher deve ir ao consultório ginecológico periodicamente para realizar o exame preventivo. O presente estudo tem como objetivos identificar se a vacinação contra o HPV é acessível para toda a população destinada e se os métodos para diagnóstico precoce se aplicam à realidade das mulheres.

\section{MÉTODOS}

Trata-se de revisão integrativa da literatura, que inclui análise de artigos científicos relevantes publicados entre os anos de 2010 e 2021 e indexados nas bases de dados: LILACS, SCIELO e MEDLINE, nos quais foram aplicados os descritores: "câncer de colo uterino, HPV, infecção e vacinação". Na seleção dos artigos foram utilizados como critérios de inclusão: artigos publicados nos últimos 11 anos, artigos publicados em português ou inglês, artigos originais e publicados na íntegra gratuitamente, e como critério de exclusão: publicações em formato de dissertação ou tese. Foram selecionados 40 artigos para leitura, sendo utilizados 29 para a elaboração final do trabalho.

Figura 1 - Fluxograma com processo de busca dos artigos.

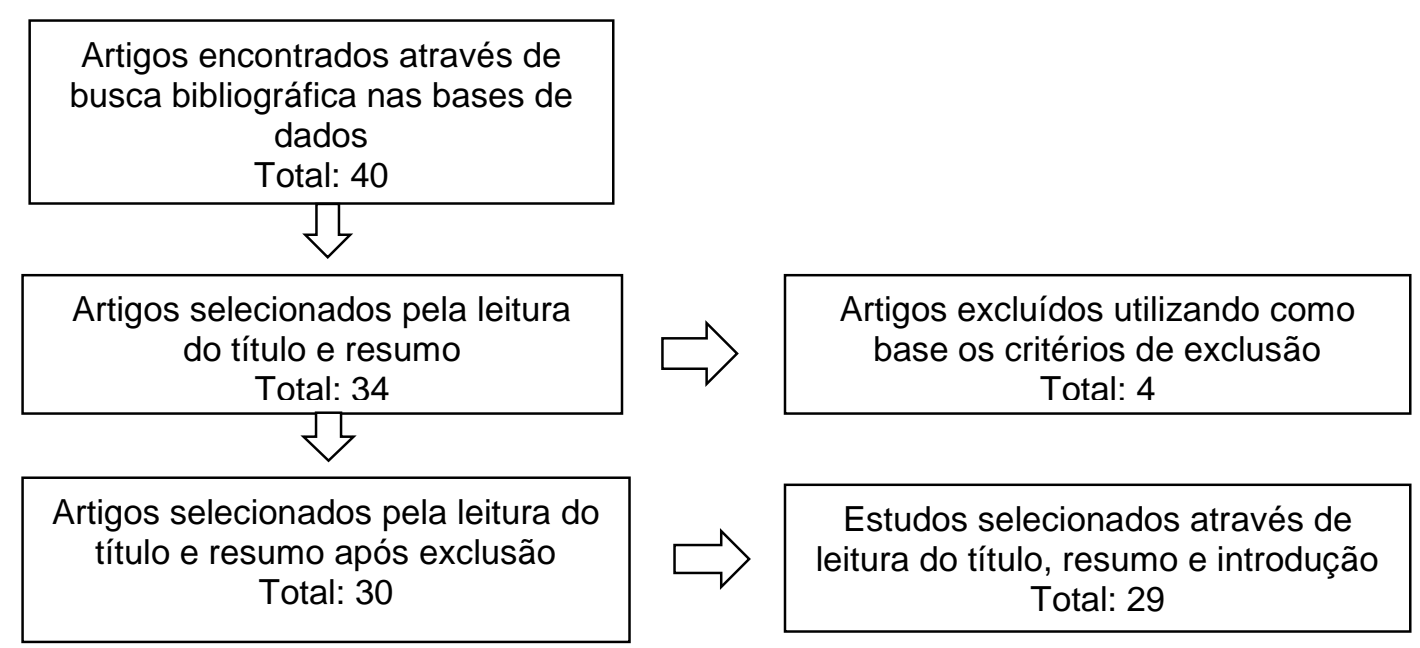

Fonte: Rodrigues LG, et al., 2021.

\section{RESULTADOS E DISCUSSÃO}

O câncer de colo do útero, também conhecido como câncer cervical, é um tumor que se desenvolve no colo uterino, localizado no fundo do canal vaginal. Esse é o terceiro tumor maligno mais frequente entre as mulheres e a quarta causa de morte por câncer na população feminina. É uma doença que pode ser detectada em exames de rotina e tem altas taxas de incidência e mortalidade (INCA, 2016).

A principal etiologia atribuída ao câncer cervical é a infecção pelo HPV, mas existem outras causas como início precoce da atividade sexual, multiplicidade de parceiros, tabagismo, uso de métodos contraceptivos orais, histórico de verrugas genitais e pacientes portadoras de doenças imunossupressoras (KJELLBERG L, et al., 2010). Nos estágios iniciais, a doença se manifesta de forma assintomática ou com poucos sintomas. Em estágios avançados a paciente pode referir secreção vaginal fétida, sangramento pós-coital, dor em região ventral, ciclos menstruais irregulares, anemia, dor lombar e alterações miccionais (CORRÊA CSL, et al., 2016). 
A infecção pelo HPV é considerada a infecção sexualmente transmissível (IST) de maior incidência no mundo. A estimativa é que haja cerca de 600 milhões de pessoas infectadas pelo HPV em todo o mundo e que $80 \%$ da população sexualmente ativa já tenha entrado em contato com o vírus em algum momento da vida (BRASIL, 2013).

A prevenção contra os tipos oncogênicos do HPV é feita através da vacinação, incorporada ao calendário vacinal do Sistema Único de Saúde (SUS) em 2014. As vacinas são profiláticas e feitas a partir de partículas semelhantes ao capsídeo viral (VLP - vírus like particles), estas partículas não possuem o DNA viral e, portanto, não causam a doença. O efeito da vacinação consiste na produção de anticorpos contra o capsídeo viral após a inoculação de VLP, a presença desses anticorpos no líquido intercelular inativa o HPV quando entram em contato com ele (SCHIFFMAN M, 2011).

No Brasil dois tipos de vacinas são utilizados na prevenção contra o vírus: a vacina quadrivalente, que confere proteção contra os tipos $6,11,16$ e 18; e a vacina bivalente que protege contra os tipos 16 e 18 . Em 2014, nos Estados Unidos, foi aprovada a vacina nonavalente contra os tipos 6, 11, 16, 18, 31, 33, 45, $52 \mathrm{e}$ 58 de HPV (HARPER DM e DEMARS LR, 2017). A eficácia máxima da vacinação ocorre quando ela é aplicada antes do início da vida sexual, quando ainda não há risco de infecção. Por outro lado, estudos demonstraram que a vacina pode ter efeito positivo em mulheres que já foram expostas ao vírus, uma vez que confere proteção adicional já que os anticorpos produzidos pelo próprio organismo não são suficientes para combater a infecção pelo HPV, além disso, as evidências sugerem que quanto maior a cobertura vacinal para meninas, menor será a chance de infecção por HPV nos meninos (AYRES AGR, et al., 2010).

O Programa Nacional de Imunizações (PNI) disponibiliza a vacina para meninas entre 9 a 14 anos e meninos entre 11 a 14 anos de idade, sendo realizadas duas doses com intervalo de 0 e 6 a 12 meses. Mulheres e homens com HIV ou imunossupressão por transplante ou tratamento oncológico podem ser vacinados entre 9 e 26 anos de idade, com três doses e intervalo de 0,2 e 6 meses. A Sociedade Brasileira de Pediatria (SBP), a Sociedade Brasileira de Imunizações (SBIm) e a Federação Brasileira das Associações de Ginecologia e Obstetrícia (Febrasgo) recomendam a vacinação de pacientes do sexo feminino entre 9 a 45 anos de idade (BRASIL, 2013).

É importante ressaltar que o Brasil é o primeiro país da América do Sul e o sétimo do mundo a oferecer a vacina contra o HPV para meninos em programas nacionais de imunizações (BRASIL, 2017). Entretanto, - Brasil apresenta dificuldades para atingir a meta de cobertura devido a não adesão de algumas estratégias como a vacinação em escolas públicas, estratégia essa adotada por países desenvolvidos e que apresenta bons resultados.

Apesar da eficácia comprovada, a imunização não atinge todo o público alvo como deveria porque ainda existe um conhecimento limitado sobre o câncer de colo de útero e sua relação com o HPV, há incerteza em relação à eficácia da vacina, desconhecimento sobre o HPV, falta de consentimento dos pais dos adolescentes em relação à prática sexual, falta de acesso a consultas na atenção primária, desconhecimento do risco da infecção pelo HPV entre homens homossexuais, dentre outros motivos (GLENN BA, et al., 2015).

Em relação ao rastreamento do câncer de colo de útero, o Ministério da Saúde estabelece que deve ser feito exame citológico (Papanicolau) em mulheres com mais de 25 anos que já deram início à vida sexual. A recomendação é que sejam feitos dois exames com intervalo de 1 ano entre eles, caso o resultado para HPV seja negativo, o mesmo exame deve ser repetido com intervalo de 3 anos. O rastreamento pode ser interrompido aos 64 anos em mulheres com pelo menos dois exames negativos consecutivos nos últimos cinco anos e sem antecedentes de patologia cervical (INCA, 2017).

Quadro 1 - Principais dados.

\begin{tabular}{|c|c|}
\hline População estudada & Mulheres entre 25 e 64 anos \\
\hline Incidência do HPV nos casos de câncer cervical & $>99 \%$ \\
\hline $\begin{array}{c}\text { Porcentagem de mulheres brasileiras que nunca } \\
\text { realizaram o exame "Papanicolau" }\end{array}$ & $40 \%$ \\
\hline
\end{tabular}

Fonte: Rodrigues LG, et al., 2021. 
Mulheres previamente submetidas à histerectomia total por lesões benignas, sem história previa de diagnostico ou tratamento de lesões cervicais de alto grau, podem ser excluídas do rastreamento, desde que apresentem exames anteriores normais. Em mulheres imunossuprimidas o exame citológico deve ser realizado após o início da atividade sexual com intervalos semestrais no primeiro ano e, se normais, manter seguimento anual enquanto se mantiver o fator de imunossupressão (BRASIL, 2013). Contudo, o "Manual Técnico de Prevenção do Câncer do colo do útero" apontou que em 2002, 40\% das mulheres brasileiras nunca tinham sido submetidas ao exame de Papanicolau. $O$ que mostra que ainda há uma deficiência no sistema de saúde para combater o câncer cervical.

A detecção precoce deste tipo de neoplasia maligna, realizada através do Papanicolau, quando associada ao tratamento da lesão intraepitelial pode reduzir em cerca de $90 \%$ a incidência do câncer cervical, o que garante uma importante diminuição nas taxas de morbimortalidade por essa afecção (MENDONÇA VG, et al., 2014). Porém, esse resultado depende da qualidade dos exames realizados e da assiduidade das mulheres, uma vez que o diagnóstico tardio dificulta o acesso à rede de atenção básica de saúde e está relacionado a um pior prognóstico para a paciente. É possível identificar alguns fatores que contribuem para o diagnóstico tardio, como: baixa capacitação profissional na atenção básica, dificuldade dos gestores em estabelecer um fluxo nos diversos níveis assistenciais e incapacidade das unidades de saúde em absorver a grande demanda que é atribuída (BRASIL, 2016).

O câncer de colo de útero é uma enfermidade que apresenta condição traçadora, pois atende aos requisitos básicos como ter alta prevalência e impacto significativo na saúde; possui etiologia, diagnóstico, terapia e forma de prevenção bem definidos pela ciência e existência de programa nacional consolidado que envolve todos os níveis assistenciais, além de ser uma doença de evolução lenta que apresenta tratamento eficaz (BOTTARI CMS, et al., 2012).

Existe uma maior frequência de realização do Papanicolau entre as mulheres mais jovens, com idade inferior a 40 anos, devido a alguns eventos como gravidez, necessidade de uso de métodos contraceptivos e acometimento por certas afecções ginecológicas, o que leva essas mulheres a procurarem mais vezes pelo médico ginecologista e, consequentemente, realizar o exame ginecológico mais vezes (AMORIM VMSL, et al., 2016). Dessa forma, a cobertura para mulheres com idade mais avançada se torna ainda mais insuficiente, o que explica o aumento dos casos de câncer de colo uterino em mulheres com idade superior a 50 anos (VALE DBAP, et al., 2014). Uma estratégia para melhorar essa situação seria convidar as mulheres mais velhas que comparecem à unidade de saúde por outros motivos a realizar o exame de Papanicolau.

A preocupação com as mulheres que tem idade superior a 50 anos é grande, pois foi observado que as alterações malignas como adenocarcinoma e carcinoma são diagnosticadas com maior frequência em mulheres que tem entre 50 e 59 anos de idade. Por outro lado, as alterações benignas e pré-malignas, estão mais presentes em mulheres com idade entre 25 e 39 anos (INCA, 2017). Existem alguns fatores que dificultam a adesão das mulheres na realização do exame como vergonha, o desconhecimento sobre a importância do exame, medo, objeção do companheiro, temor da doença, inatividade sexual, nível socioeconômico e cultural (PINHO AA e FRANÇA Jl, 2013).

\section{CONSIDERAÇÕES FINAIS}

Observou-se que apesar de existirem políticas públicas voltadas para a prevenção do câncer do colo uterino, a incidência dessa doença ainda é grande entre a população. Tal circunstancia decorre da falta de adesão à vacinação contra o HPV, vírus causador do câncer de colo de útero, e do grande número de mulheres que não realizam exames ginecológicos periodicamente, visto que uma parcela considerável da população feminina não conhece os riscos associados à infecção pelo HPV. Dessa forma, é necessário que haja uma intensificação na divulgação das medidas preventivas para que um maior número de mulheres tenha acesso a essas informações, sabendo que a prevenção da doença é simples e feita em âmbito de atenção básica de saúde, além do diagnóstico precoce garantir um melhor prognóstico para a paciente. 


\section{REFERÊNCIAS}

1. AMORIM VMSL, et al. Fatores associados à não realização do exame de Papanicolaou: um estudo de base populacional no Município de Campinas, São Paulo, Brasil. Cad Saude Publica. 2016; 11-21.

2. AYRES AGR, Azevedo e Silva G. Prevalência de Infecção do colo do útero pelo HPV no Brasil: revisão sistemática. Rev Saude Publica 2010; 18-22.

3. BERNARD HU, et al. Classification of papillomavirus based on 189 PV types and proposal of taxonomic amendments. Virology, 2010; 35-42.

4. BOTTARI CMS, et al. Câncer cérvico-uterino como condição marcadora: uma proposta de avaliação da atenção básica. Cad Saude Publica. 2012; 24-31.

5. BRASIL. Guia prático de vacinação da mulher. São Paulo: Sociedade Brasileira de Imunizações (SBIm); Federação Brasileira das Associações de Ginecologia e Obstetrícia (Febrasgo); 2014; 24-33.

6. BRASIL. Ministério da Saúde. Gabinete do Ministro. Portaria № 3.388, de 30 de dezembro de 2013. Institui a Qualificação Nacional em Citopatologia na prevenção do câncer do colo do útero (QualiCito), no âmbito da Rede de Atenção à Saúde das Pessoas com Doenças Crônicas, 2013.

7. BRASIL. Ministério da Saúde. Instituto Nacional de Câncer. Nomenclatura Brasileira para Laudos Cervicais e Condutas Preconizadas: recomendações para profissionais de saúde. J Bras Patol Med Lab. 2016; 17-25

8. BRASIL. Ministério da Saúde. Nota informativa 384. Mudanças no calendário nacional de vacinação de 2017. Brasília (DF): Programa Nacional de Imunizações; 2017; 1-22.

9. BRASIL. Ministério da Saúde. Prevenção do câncer do colo do útero. Manual técnico: profissionais de saúde. Brasília, 2012; 10-37.

10. CORRÊA CSL, et al. Sexual function of women surviving cervical cancer. Arch Gynecol Obstet. 2016; 24-37.

11. DALY SF, et al. Can the number of cigarettes smoked predict high-grade cervical intraepithelial neoplasia among women with mildly abnormal cervical smears? Am J Obstet Gynecol. 2011; 2-10.

12. GLENN BA, et al. Factors associated with HPV awareness among mothers of low-income ethnic minority adolescent girls in Los Angeles. Vaccine. 2015; 33 (2): 289-293.

13. HARPER DM, DEMARS LR. HPV vaccines: a review of the first decade. Gynecol Oncol. 2017; 88-97.

14. INSTITUTO NACIONAL DE CÂNCER (INCA). Coordenação de Prevenção e Vigilância. Divisão de Detecção Precoce e Apoio à Organização de Rede. Manual de gestão da qualidade para laboratório de citopatologia. 2. ed. rev. ampl. Rio de Janeiro: INCA, 2016.

15. INSTITUTO NACIONAL DE CÂNCER (INCA). Diretrizes brasileiras para o rastreamento do câncer do colo do útero. 2 ed. rev. ampl. atual. Rio de Janeiro: INCA, 2016; 14-35.

16. INSTITUTO NACIONAL DE CÂNCER (INCA). Estimativa 2018: incidência de câncer no Brasil. Rio de Janeiro: INCA, 2017; 2-5.

17. INSTITUTO NACIONAL DE CÂNCER (INCA). Estimativa câncer de colo para 2016. Rio de Janeiro: INCA; $2016 ; 2-4$.

18. INTERNATIONAL FEDERATION OF GYNECOLOGY \& OBSTETRICS (FIGO). Global guidance for cervical cancer prevention and control. Geneva: FIGO; 2010; 4-17.

19. KJELLBERG L, et al. Smoking, diet, pregnancy and oral contraceptive use as risk factors for cervical intra-epithelial neoplasia in relation to human papillomavirus infection. Br J Cancer 2010; 5-21.

20. MENDONÇA VG, et al. Mortalidade por câncer do colo do útero: características sociodemográficas das mulheres residentes na cidade de Recife, Pernambuco. Rev Bras Ginecol Obstet. 2014; 30-37.

21. NEVES NA. Vacinação de mulher: manual de orientação. São Paulo: Febrasgo; 2010; 2-8.

22. PINHO AA, FRANÇA JI. Prevenção do câncer de colo do útero: um modelo teórico para analisar o acesso e a utilização do teste de Papanicolaou. Rev Bras Saude Mater Infant. 2013; 12-18

23. RABACHINI T, et al. Biologia do HPV. In Consolaro MEL, Maria-Engler SS, editors. Citologia clínica cérvico-vaginal. São Paulo: Roca; 2012; 3-13.

24. SASAGAWA T, et al. Immune responses against human papillomavirus (HPV) infection and evasion of host defense in cervical cancer. J Infect Chemother, 2012; 43-57.

25. SCHIFFMAN M. Integration of human papillomavirus vaccination, cytology, and human papillomavirus testing. Cancer. 2011; 31-42.

26. VALE DBAP, et al. Avaliação do rastreamento do câncer do colo do útero na Estratégia Saúde da Família no Município de Amparo, São Paulo, Brasil. Cad Saude Publica. 2014; 7-15

27. VILLIERS EM. Cross-roads in the classification of papillomaviruses. Virology, 2013; $2-4$.

28. WORLD HEALTH ORGANIZATION (WHO). ICO. Information Centre on HPV and Cervical Cancer (HPV Information Centre). Human papillomavirus and related cancers in world. Summary Report 2016. Geneva: WHO, 2016; 7-21. 